\title{
Serious Game Top Eleven as an Educational Tool in Sports Economics
}

\author{
Afthinos, Ioannis ${ }^{1}$, Manasis, Vasileios ${ }^{1}$, Chrysanthopoulos, Thodoros-Panagiotis ${ }^{1 .}$ \\ ${ }^{1}$ National and Kapodistrian University of Athens, \\ iafthinos@phed.uoa.gr, \\ vmanasis@phed.uoa.gr, \\ thodorischrysanthopoulos@gmail.com
}

\begin{abstract}
The present study aims to explore the use of the serious game Top Eleven as an auxiliary educational tool in a sports economics undergraduate course. This attempt is warranted because serious games can provide real life/work experiences and set the ground for managerial - economics skills development. The selection of the specific serious game is based on the ample and varied sports economics data provided and its free of charge online accessibility. Following the case study methodology, a virtual football club was created and managed within Top Eleven. The stated research questions were based on the analysis and application of the generated data to a number of economic concepts identified in a specific sports economics textbook. Based on the analysis results, twelve out of 17 in total identified economic concepts were successfully analyzed using eleven economic data sources of items embedded in the game. The implementation phase showed that Top Eleven could be used as an educational supporting tool in the form of a virtual internship to gain practical experience by applying sports economic concepts for the financial management of a professional football club. It is argued that the game offers a sensible working environment in sports economics and the associated sport management field.
\end{abstract}

Keywords: Economics IT educational tool, serious games, digital games, sport management, sports economics, Top Eleven

\section{Introduction}

Since the beginning of the twenty-first century, technology has made its appearance and constitutes an integral part of our daily lives. On this development, the contemporary educational process has built its foundations. During the 19th century, education was considered a process based on "learning knowing". On the contrary, 21st century necessitates flexibility and acquisition of skills; that is, "learning by doing" [1]. This modern educational orientation can be implemented either with an internship in real work environments, or with a digital internship in virtual work environments. For instance, in the science of medicine, the training of young doctors is accomplished with the help of educational simulations in the specialty of surgery [2].

Modern technology allows the simulation of almost any physical activity in the form of digital games, where the learner acquires an online character-personality acting in an environment that simulates the real world [3]. The games can provide various difficulty options; therefore, they are also useful for the educational process since they can be adapted 
to students-gamers' abilities [4]. Another crucial reason for games' inclusion in the educational process is gamers' motivation through fun offering [5]. This feature is reinforced by the results from Paraskeva, Mysirlaki \& Papagianni [6] that young people in Greece spent 2.53 hours a day on digital games, suggesting that educational games could exploit from this inclination by offering a basis for an innovative and motivating homework. Based on the empirical research of Papp [7], gamification positively affects intrinsic and extrinsic motivation, engagement and learning outcomes for students at college level.

A number of researchers have tried to categorize digital games into general genres [8], [9]. In a more recent work, Aldrich [1] suggests that digital games are classified by type into three categories as follows:

a) Videogames: They target the player's reflexive skills in fast visual stimuli of the game requiring immediate decision-making. This type includes combat games, motorsport races, sport competitions, etc.

b) Serious games: They simulate the operation of real management systems of organizations or departments. They are addressed to the player's decision-making, thus cultivating critical thinking. This category includes games for the development and management of cities, sport clubs, etc.

c) Educational simulations: They simulate real environments in which participants are asked to make specific choices to achieve specific learning objectives.

The category of serious games combines both the environment of video games and the complexity of a legal organization; therefore, it produces learning objectives in a userfriendly environment which does not exist in educational simulators [1]. Since educational simulators, as specialized software, are expensive either for acquisition or development, the educational community focused on sophisticated serious games, free of charge and easily accessible through social media. This technology evolution has been adopted by a large number of global scale educational organizations by including serious games as educational tool in their curricula [10]. According to Kretschmenn [11], serious games are not only used for fun but also employ learning processes in a specific field of work.

Based on the above, this study investigates the appropriate use of a serious game to provide practical experience in the financial management of sports organizations as part of the education of Physical Education and Sport Science students of Greek universities. Such a game could be the free-to-play online serious game Top Eleven [12], which is a multiplatform, which can be accessed via pc, tablet, and/or smartphone, that covers a broad area of a professional football team management from creating a team to stadium building [13]. Student-Gamers would have the opportunity in their usual activity to tackle with the everyday management tasks of a football club, one of which is economics engaging in: selling and signing of new players, investing on infrastructure development, setting the ticket price or making sponsoring deals. Based on the classification of sport games offered by Kretschmann [14], Top Eleven can be considered as a Sports management game like other mentioned role-playing commercial off-the-shelf games, e.g., Box Sports Manager, FIFA Manager, Football Manager, NFL Head coach. Based on the research literature, sport management games are not covered in-depth and the relevant research is considered poorly represented [11].

The present study aims to explore the use of the serious game Top Eleven as an auxiliary educational tool in a sports economics undergraduate course. This attempt is warranted by the fact that serious games can provide real-life/work experiences and set the ground for managerial - economics skills development. In fact, due to Covid19 pandemic, students have limited, if any, internship opportunities to put their knowledge in use. Furthermore, economics is a sensitive subject to any organization to be left for interns' management decision making. Therefore, serious sport games such as Top Eleven provide the opportunity to the students, through their engagement, to produce data related to the operation of a professional football club as much close to reality as possible in order to test their knowledge and skill in sport economics management. To do this, the researchers of this study perceive and use the serious game not the way it was intended to be used, but rather through an educational point of view. That is, to ask students-users to make financial 
decisions related to the game, based not on a hunch but: (a) on the use and analyses of economic concepts they have learned in a sport economics class, as well as (b) data deriving from the management of the team. To fulfill this aim, the raised research questions are as follows:

1) What basic economic concepts are included in teaching the introductory undergraduate class of sports economics?

2) What sources of operational data collected from the serious game Top Eleven could be applied to the economic concepts taught in an undergraduate sports economics class?

3) Can the serious game Top Eleven be used as an auxiliary educational tool for teaching the subject of sports economics at undergraduate level?

It follows an analysis of serious games as auxiliary educational tools, the serious game Top Eleven's main characteristics, and a description of managerial economics concepts that can be applied at a professional football club. The study proceeds with the research methodology, the presentation of the results, and the conclusive remarks highlighted by future research suggestions.

\section{Literature review}

\subsection{Serious games as educational tool}

Over the last decade, a steep increase in serious games development has been witnessed mainly due to the recent advanced information technology [15]. The value of serious games as educational tools is undisputable given that playing is an essential part of the learning process [16]. In particular, when games are serious and focused to a specific environment can help students construct a reflective understanding [17]. The benefits from using them as companions to classroom instruction is documented by researchers [18]-[21]. Serious games are an excellent tool for transmitting educational contents both attractively and effectively, especially in periods of economic and social crisis [22]. According to Noemí and Máximo [22], the main characteristic of serious games in attracting students' interest is that they assign students a leading role of their own learning process in a simple and dynamic way.

There are digital games that can be used as an educational tool for teaching business in various training areas such as: operations, human resource, management, organizational behavior, and finance [23]. The potential of digital games is highlighted by the decisionmaking skills adopted by upcoming managers, such as the balance between the extremes of decision-making styles; that is, the quite authoritarian to quite egalitarian [24]. The systematic use of serious games plays a crucial positive role in gaining experiences in management knowledge and skills [25]. Games in economics concerned with organizations' financial operation have appeared in European higher education institutions since the 1930s [26]. Recently, financial games have been developed and introduced into the curriculum of institutions such as the Saunders College of Business at Rochester Institute of Technology [26]. A method proposed by Jerčić [27] intended to improve gamers' decision-making performance in the context the Auction Game (a financial serious game) using biofeedback measurement. The participants of the game were twenty-one students instructed to buy or sell a given stock, based on the mean value of three price estimations and the offered price. It is noted that price estimations were directly associated with the physiological arousal level; that is, the more aroused the student was, the more diverged from the correct price.

In the sport context, based on Kretschmann [14], there are some sport management games in which the gamer can deal with reality-based economic and financial problems, by assuming the leadership of a sports club. More specifically, the gamer cannot intervene to any specific sports action on the court, but uses the sport only from the view of person in a 
pag. 6

leading management position. Based on the work of Kretschmann [11], the game FIFA Manager 09 might provide an opportunity for gamers to acquire skills and tasks found in the reality of sport management and generally in the field of management. Similarly, the Oakland A's Baseball Business Simulator seems to be highly effective in helping students both engage in the decision-making process and retain concepts effectively [28]. McFarlane et al. [29] found that games, including the sport management game Championship Manager (football), support the development of a wide range of skills essential to the self-directed learner. The chosen games had apparent curriculum relevance and supported a particular learning style, parents' evidenced home use via a framework provided by teachers, while a focus group among teacher evaluators had been developed to identify learning outcomes and highlight management issues. However, according to Kretschmann [11], these results cannot be credited decidedly to Championship Manager due to the merge with other type of games..

\subsection{The features of the serious game Top Eleven}

Top Eleven, which has been released by Nordeus in 2010, is a game about managing various assets of a virtual football club (players, facilities, tickets, sponsors, demanding economic strategy by the gamers [30]. The basic description of this free of use serious game contains the following parameters (Figure 1):

- Based on the playing level, a football club is automatically assigned to participate in multiple competitions (Championship, Champions League, League Cup). Additionally, friendly matches can be scheduled freely by selecting opponents through Facebook.

- Club's playing performance depends mainly on the players': value, transfer market, contract renewal, as well as training method, quality, and level.

- In any season, there are 28 daily games lasting 30 minutes each with no gamer involvement.

- Gamer's involvement ranges from inactivity (the club participates in games automatically) to hourly long daily decision making.

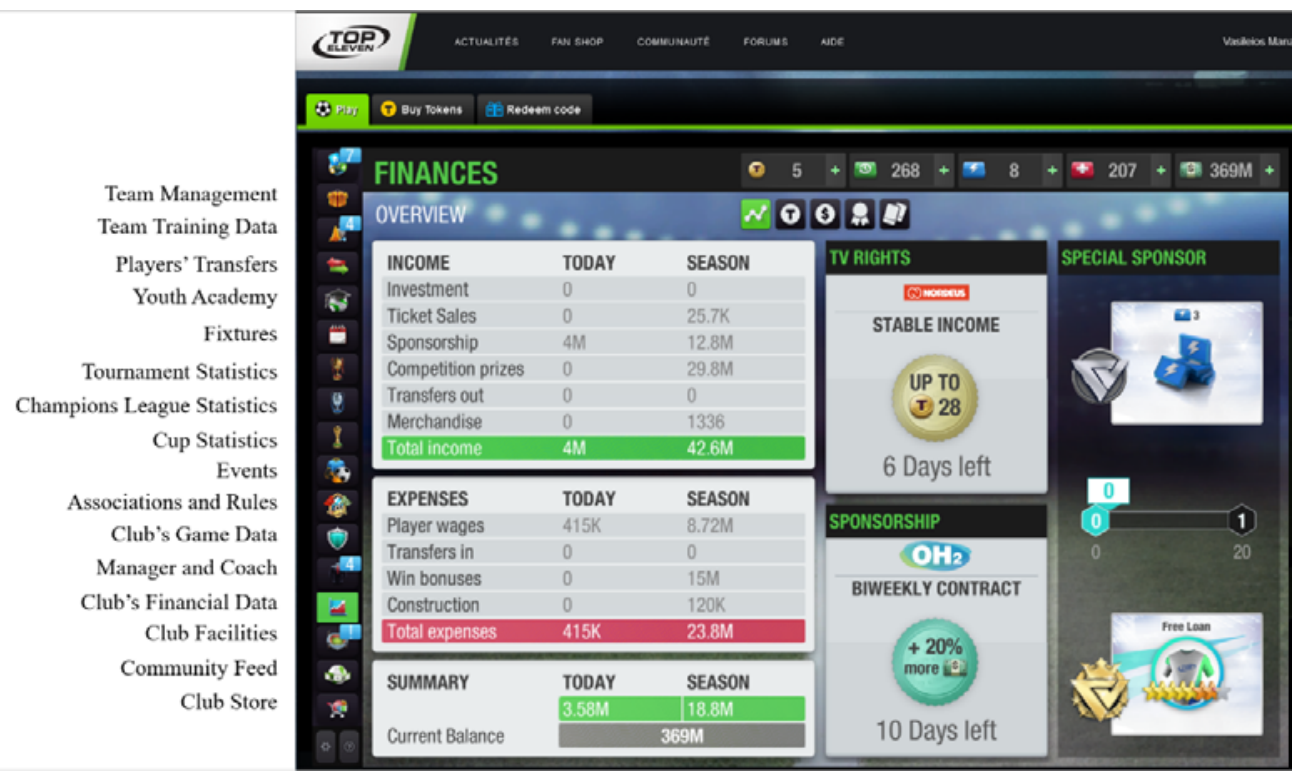

Figure 1. Top Eleven's main menu

Furthermore, the game offers tasks and options comparable in complexity to real world sport management decision-making. In particular it provides economic parameters, among 
others, to the extent that can be used as a simulator focused on the managerial economics of a professional football club. Afthinos [31, p. 222] notices that Top Eleven satisfactorily resembles the management environment of a professional football club featuring the following: Top Eleven holds managerial features concerning decision making process based on facts (i.e. competition draws \& results) and economic data (i.e. stadium construction cost, ticket prices), that affect both club's performance and growth. Furthermore, the gamer is engaged with various management initiatives (i.e. player transfer, contract renewal) for club's continuous improvement. Based on managerial actions, more revenue and higher performance on the field of play is generated. As a result, the football club advances to higher competitive leagues, which is the aim of the game.

In this respect, sport management majoring students in the Department of Physical Education \& Sport Science (DPESS) at the National \& Kapodistrian University of Athens, have been using the serious game Top Eleven for the management of a professional football club, in every part of their educational process: lectures, exercises, role-playing, and participation in competitions as part of their virtual practical training.

Based on the above, following Kretschmann's classification [14], Top Eleven can be considered a sport management game. Therefore, we argue that we can use the game Top Eleven as an auxiliary educational tool, since it displays a clear purpose other than just entertainment following the definition of serious games as described by Susi, Johannesson, and Backlund [32].

\subsection{Management of a sport club}

The management of a professional sport club includes functions such as: sport, economics, marketing, facilities and operations [31]. Furthermore, it shall include an integrated management control system [33]-[37]. Control is the process that ensures that the objectives are met through information derived from work with regard to the achievement of the stated objective. A control system compares process information with the expected work outcome standards and based on the result leads to management decisions [38]. Therefore, work performance indicators should be set up in each of the abovementioned management areas of a professional football club as part of a management information system ensuing proper decision-making [34], [37], [39]. Offsetting all management indicators results, exhibits an overview of the organization's performance [38] and should be collected from its operation.

Economics is a field of study that affects our everyday life in many ways [40]. According to Leeds and von Allmen [40], "The challenge that faces students of economics is to learn just how all-encompassing the effects are and to develop the tools to understand them. That is where sports come in. Sports are a pervasive factor in how people feel about their communities and themselves". The field of sports economics covers a wide area of economic principles and students can better understand basic economic concepts through the lens of sports [40].

Furthermore, the management of a sports club economics is achieved through accounting [41]. Accounting is a basic function of managerial economics since it collects, classifies, registers, and analyses all economic related data [42] as well as provides the company's economic results statement at regular intervals [41]. Consequently, economics is an important function of a professional sports club; thus, it constitutes a distinct academic subject. The subject of sports economics is taught at undergraduate level in DPESS, as an obligatory course, into the curriculum of sport management specialization.

\section{Research methodology}

Research design and purpose. This is a case study with the intent to examine whether the serious game Top Eleven can be used as an educational auxiliary tool for teaching the subject sports economics in DPESS. 


\subsection{Research Procedures}

The researchers took the following steps:

First, they selected a trendy auxiliary teaching means in form of a serious game. Top Eleven was selected based on the following criteria: (a) its sport popularity (football), (b) its cost free availability (c) its easy multi-platform access, and (d) its advanced procedures on the economic management of a football club.

Second, the researchers content analyzed the textbook taught in the sport economics class "Economics of sport administration. Introductory concepts and applications" (in Greek) [43] in order to identify economic concepts. For the extraction of the data a content analysis protocol was used based on the Conceptual content analysis and Weber's [44] Content Analysis Directive. More specifically, following the approach of Leeds von Allmen [40], the class book was content analyzed guided by the basic economic concepts of supply, demand, cost and pricing. Beyond these, there was researched the concept of budget (accounting) since it is a basic function of managerial economics closely related with the management of a sports club economics [41].

Following, the researchers created a virtual football club (within the serious game Top Eleven) to examine whether the identified economic and accounting concepts in step two can be applied to the management of the virtual football club. Then, the researchers proceeded to, the game-play analysis intended to collect economic data during and as result of the educational questions intended to be answered through the operation of the game. The sample data ranged seven consecutive game seasons each lasting 28 days. Based on the research protocol, data related to football players' contracts and transfer fees, as well as revenue sources were recorded via a research protocol at the beginning and at the end of each season. On the other hand, data related to everyday financial operation such as attendance, tickets, expenses, and championship score table, were collected via a research protocol resembling accounting procedures on a daily basis.

\subsection{Data analysis}

The data collected through the research protocols were then analyzed via the identified economic concepts to produce an economic decision aid system for the football club's financial management to be used as an innovative approach to teach (through economic concepts application) sport economics to university students. These set of analyses are illustrated with the use of descriptive statistics, figures, and computed equations as well as indices extracted via MS excel.

\subsection{Validity and reliability}

The validity of the research is based on the analysis of the derived economic data, with concern to the assumptions of the investigated sport economic concepts. Research is reliable since data is generated by game algorithms and analyzed with economic functions. Our limitation is that this study's results are based on the researchers' data collection and analysis. Therefore, student validation of the education value of our proposal is needed as further research.

\section{Results}

The present study aims to explore the use of the online serious game Top Eleven as an auxiliary educational tool for the economics of a professional football club. Regarding the first research question stating: "What basic economic concepts are included in teaching the introductory undergraduate class of sports economics?" from the content analysis of the 
sports economics textbook taught in DPESS, there were identified 17 in total economic concepts as shown in Table 1.

Table 1. Identified economic concepts \& data sources from Top Eleven

\begin{tabular}{l|l}
\hline Economic concept & Economic data source from Top Eleven \\
\hline 1. Price elasticity of supply & 1. Attendance per game \\
\hline 2. Supply curve & 2. Stadium capacity \\
\hline 3. Supply function & 3. Ticket price \\
\hline 4. Price elasticity of demand & 4. Prize bonus \\
\hline 5. Demand curve & 5. Value of players' contract \\
\hline 6. Sport product appeal & 6. Revenue and players' transfer fee \\
\hline 7. Demand function & 7. Prize money \\
\hline 8. Market equilibrium & 8. Revenue from sponsorship \\
\hline 9. Direct \& indirect cost & 9. Revenue from merchandising \\
\hline 10. Fixed \& variable cost & 10. Stadium and facilities expenses \\
\hline 11. Marginal cost & 11. Championship score table \\
\hline 12. Break-even point analysis & \\
\hline 13. Method of total cost absorption & \\
\hline 14. Method of marginal cost & \\
\hline 15. Pricing & \\
\hline 16. Budget & \\
\hline 17. Balance sheet & \\
\hline
\end{tabular}

Regarding the second research question, stating: "What sources of operational data collected from the serious game Top Eleven could be applied to the economic concepts taught in an undergraduate sports economic class?" There are found 11 economic sources producing data that can be collected from Top Eleven game's operation and could be applied for auxiliary gamification-based teaching of economic concepts from the field of sports (see Table 1). The followed analysis is based on the possible actions that the studentgamer has within the gaming environment [11].

Based on Table 2, most of the identified economic concepts in Table 1 can be indeed implemented using the derived data items. In particular, 12 out of the 17 in total economics concepts can be taught using the game as an auxiliary tool, were students apply-test-gain financial management experience. The missing economics concepts from Table 1 is mainly due to lack of data availability based on the data produced by Top Eleven.

Table 2. Applied economic concepts, the employed Top Eleven data sources and relevant presenting type by number.

\begin{tabular}{|c|c|c|c|}
\hline Applied economic concept & Top Eleven data source & Table & Figure \\
\hline 1. Price elasticity of demand & $\begin{array}{l}\text { Ticket price } \\
\text { Attendance }\end{array}$ & 3 & \\
\hline 2. Demand curve & $\begin{array}{l}\text { Ticket price } \\
\text { Attendance }\end{array}$ & & 2 \\
\hline 3. Sport product appeal & Championship score table & 4 & 3 \\
\hline 4. Price elasticity of supply & $\begin{array}{l}\text { Ticket price } \\
\text { Stadium capacity }\end{array}$ & 5 & \\
\hline 5. Supply curve & $\begin{array}{l}\text { Ticket price } \\
\text { Stadium capacity }\end{array}$ & 5 & 4 \\
\hline
\end{tabular}


pag. 10

6. Market equilibrium

7. Direct \& indirect cost

8. Fixed \& variable cost

9. Marginal cost

10. Break-even point analysis

11. Pricing

12. Budget

\begin{tabular}{l|l|l} 
Ticket price & & 5 \\
Stadium capacity & & \\
Attendance & 6 & \\
$\begin{array}{l}\text { Value of players' contract } \\
\text { Players' transfer fee }\end{array}$ & & \\
Stadium \& facilities expenses & 7 & \\
$\begin{array}{l}\text { Stadium \& facilities expenses } \\
\text { Prize bonus }\end{array}$ & 8 & \\
Stadium capacity & & \\
Stadium and facilities expenses & & 6 \\
$\begin{array}{l}\text { Attendance } \\
\text { Ticket price }\end{array}$ & 8 & \\
Stadium and facilities expenses & & \\
$\begin{array}{l}\text { Stadium capacity } \\
\text { Stadium and facilities expenses }\end{array}$ & \\
$\begin{array}{l}\text { Attendance } \\
\text { Ticket price }\end{array}$ & \\
Prize money & \\
Revenues from Players' transfer \\
Revenue from merchandising \\
Value of players' contract \\
Players' transfer fee \\
Prize bonus
\end{tabular}

Concerning the third research question stating that "Can the serious game Top Eleven be used as an auxiliary educational tool for teaching the subject of sports economics at undergraduate level?", based on the application of the 12 economic concepts to the operation of the serious game, the following sets of analyses - results were produced:

1. The first economic concept (Table 2, point 1) of "price elasticity of demand $\left(\mathrm{e}_{\mathrm{d}}\right)$ ", can be applied to the game by using the price $(\mathrm{P})$ and the quantity of bought tickets $\left(\mathrm{Q}_{\mathrm{d}}\right)$ which is equivalent to stadium attendance. The formula of $\mathrm{e}_{\mathrm{d}}$ is given by:

$$
\mathrm{e}_{\mathrm{d}}=\frac{\Delta \% \mathrm{Q}_{\mathrm{d}}}{\Delta \% \mathrm{P}}
$$

where $\Delta \% \mathrm{Q}_{\mathrm{d}}$ denotes the percentage change in the number of tickets bought and $\Delta \% \mathrm{P}$ denotes the percentage change in tickets' price bought by the fans. On the implementation results in Table 3, there are shown that the gamers-students can gain experience in both the effect of ticket price changes on attendance and the steps for the calculation of demand elasticity. Note that the first column in Table 3 stands for the numbering of the competition days during the championship season.

Table 3. Price elasticity of ticket demand

\begin{tabular}{c|c|c|c|c|c}
\hline Day & $\mathbf{P}$ & $\mathbf{Q}_{\mathbf{d}}$ & $\mathbf{\Delta} \mathbf{\%} \mathbf{P}_{\mathbf{t}}$ & $\mathbf{\Delta} \mathbf{\%} \mathbf{Q}_{\mathbf{d}}$ & $\mathbf{e}_{\mathbf{d}}$ \\
\hline 1 & $20.0 €$ & 73000 & 0.300 & -0.158 & -1.888 \\
\hline 3 & $26.0 €$ & 61400 & -0.076 & 0.074 & -1.027 \\
\hline 5 & $24.0 €$ & 66000 & 0.833 & -0.166 & -0.500 \\
\hline 12 & $26.0 €$ & 55000 & -0.115 & 0.140 & -0.824 \\
\hline 15 & $23.0 €$ & 62700 & -0.087 & 0.124 & -0.699 \\
\hline 20 & $21.0 €$ & 70500 & 0.428 & -0.425 & -1.007 \\
\hline 24 & $30.0 €$ & 40500 & -0.066 & & \\
\hline
\end{tabular}

2. The second economic concept of "demand curve" (Table 2, point 2) is graphically depicted in Figure 2. On the horizontal and vertical axes are depicted the stadium attendance 
and price of tickets respectively. Based on curve's slope, as the theory of demand states, the game administrators-students can gain experience in a negative relation between price and quantity of tickets that is evidenced.

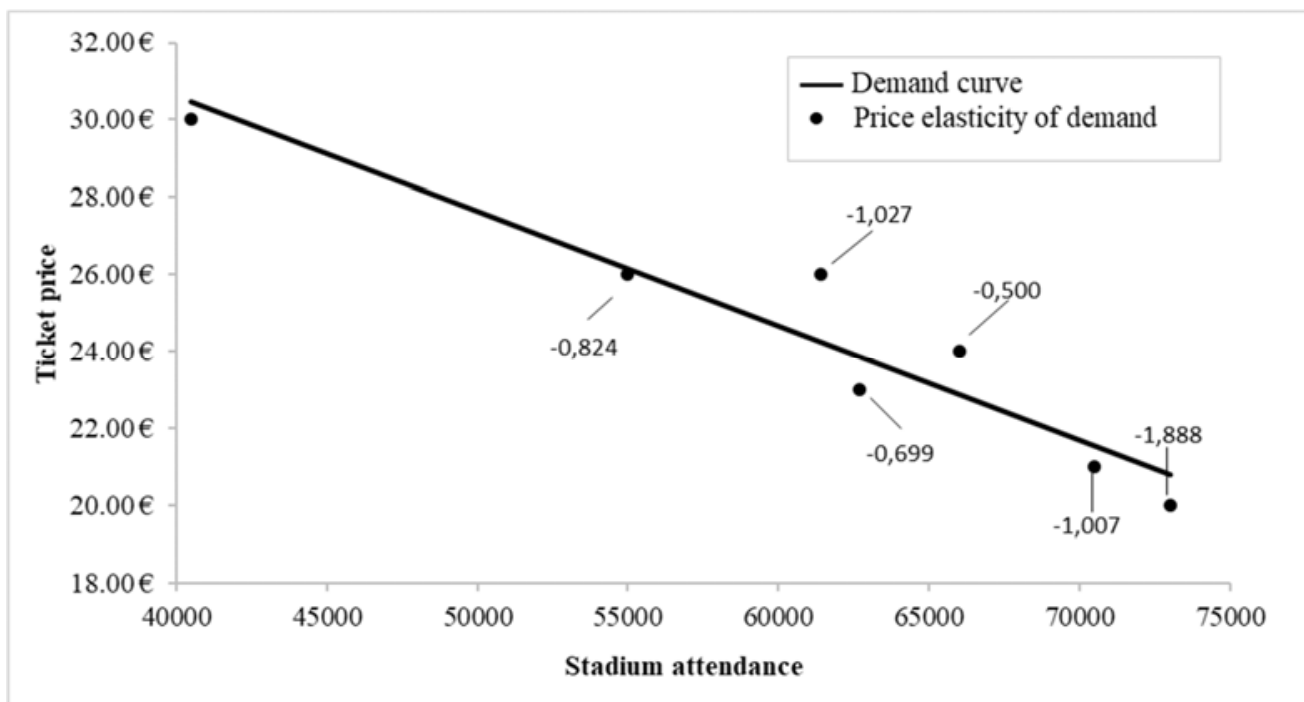

Figure 2. Demand curve and price elasticity of ticket demand

3. For the application of the third economic concept "sport product appeal" (Table 2, point 3), the uncertainty of outcome (UO) at game level derived from championship score table is employed. Based on the approach offered by Demmert [45], the absolute difference of points between home and visiting teams is taken under consideration for the calculation of UO. The absolute difference is normalized by the maximum attainable number of points as follows:

$$
\mathrm{UO}=\frac{\mid \text { Points of home team-Points of visiting team } \mid}{\text { Maximum attainable number of points }}
$$

The implementation results are presented in Table 4 and depicted in Figure 3. The UO ranges from zero to unity. For the interpretation, the game administrators-students can gain experience in learning that the lower the UO, the greater the appeal of a game. Otherwise, as UO approaches unity, the game is less attractive since there's a considerable difference in playing capabilities between the two opponent teams.

Table 4. Calculation of the uncertainty of outcome

\begin{tabular}{c|c|c|c|c}
\hline Day & $\begin{array}{c}\text { Max number } \\
\text { of points }\end{array}$ & $\begin{array}{c}\text { Home team } \\
\text { points }\end{array}$ & $\begin{array}{c}\text { Visiting team } \\
\text { points }\end{array}$ & $\begin{array}{c}\text { Uncertainty of } \\
\text { outcome }\end{array}$ \\
\hline 1 & 0 & 0 & 0 & 0.000 \\
\hline 3 & 3 & 3 & 3 & 0.000 \\
\hline 5 & 12 & 4 & 12 & 0.667 \\
\hline 8 & 21 & 13 & 19 & 0.286 \\
\hline 10 & 27 & 25 & 25 & 0.000 \\
\hline 12 & 33 & 20 & 29 & 0.273 \\
\hline 17 & 42 & 19 & 36 & 0.405 \\
\hline 19 & 48 & 7 & 42 & 0.729 \\
\hline
\end{tabular}


pag. 12

\begin{tabular}{c|c|c|c|c}
\hline 20 & 57 & 6 & 49 & 0.754 \\
\hline 22 & 63 & 28 & 53 & 0.397 \\
\hline 24 & 69 & 34 & 56 & 0.319 \\
\hline 26 & 75 & 39 & 59 & 0.267 \\
\hline
\end{tabular}

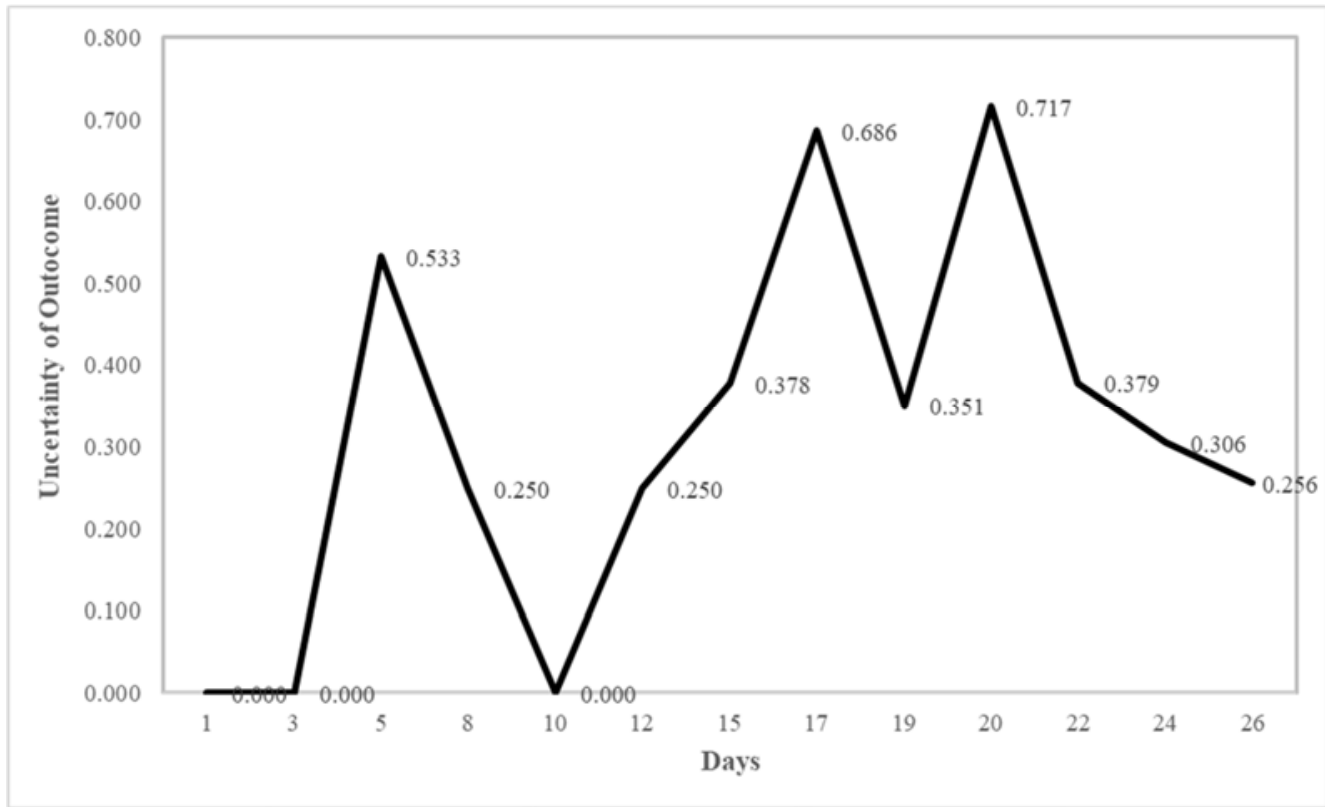

Figure 3. Uncertainty of outcome

4. The application of the fourth economic concept that is the "price elasticity of supply $\left(e_{s}\right)$ " is based on the price of tickets and the stadium capacity which is employed as a proxy for the quantity of tickets offered. Based on the economic theory, the formula for the calculation of $\left(\mathrm{e}_{\mathrm{s}}\right)$ is given by:

$$
\mathrm{e}_{\mathrm{s}}=\frac{\Delta \% \mathrm{Q}_{\mathrm{s}}}{\Delta \% \mathrm{P}}
$$

where $\Delta \% \mathrm{Q}_{\mathrm{s}}$ is the percentage change of tickets' quantity and $\Delta \% \mathrm{P}$ is percentage change of tickets' price offered by the football club. On the implementation results in Table 5, there are shown ticket price and quantity changes based on the game administrators-students' management decisions as well as the calculation of $e_{s}$. The case with a negative sign in $e_{s}$ can be explained by game's attribute to only upgrade the quantity of tickets offered, namely stadium capacity.

Table 5. Price elasticity of ticket supply

\begin{tabular}{c|c|c|c|c|c|c}
\hline Season & Day & $\mathbf{P}$ & $\mathbf{Q}_{\mathbf{s}}$ & $\boldsymbol{\Delta} \% \mathbf{P}$ & $\mathbf{\Delta} \% \mathbf{Q}_{\mathbf{s}}$ & $\mathrm{e}_{\mathrm{s}}$ \\
\hline \multirow{3}{*}{1} & 1 & $7.00 €$ & 10000 & 0.286 & 0.300 & 1.049 \\
\cline { 2 - 7 } & 5 & $9.00 €$ & 13000 & -0.286 & 0.308 & -1.076 \\
\hline \multirow{3}{*}{2} & 1 & $7.00 €$ & 17000 & 0.143 & 0.235 & 1.645 \\
\cline { 2 - 7 } & 8 & $8.00 €$ & 21000 & 0.000 & 0.238 & N/A \\
\cline { 2 - 7 } & 24 & $8.00 €$ & 26000 & - & - & - \\
\hline
\end{tabular}

5. The illustration of the fifth economic concept of the "supply curve" is based on the data presented in Table 5. As depicted in Figure 4 and according to the supply theory, the 
game administrators-students can gain experience in learning that there's a slightly positive relation between ticket price and quantity offered.

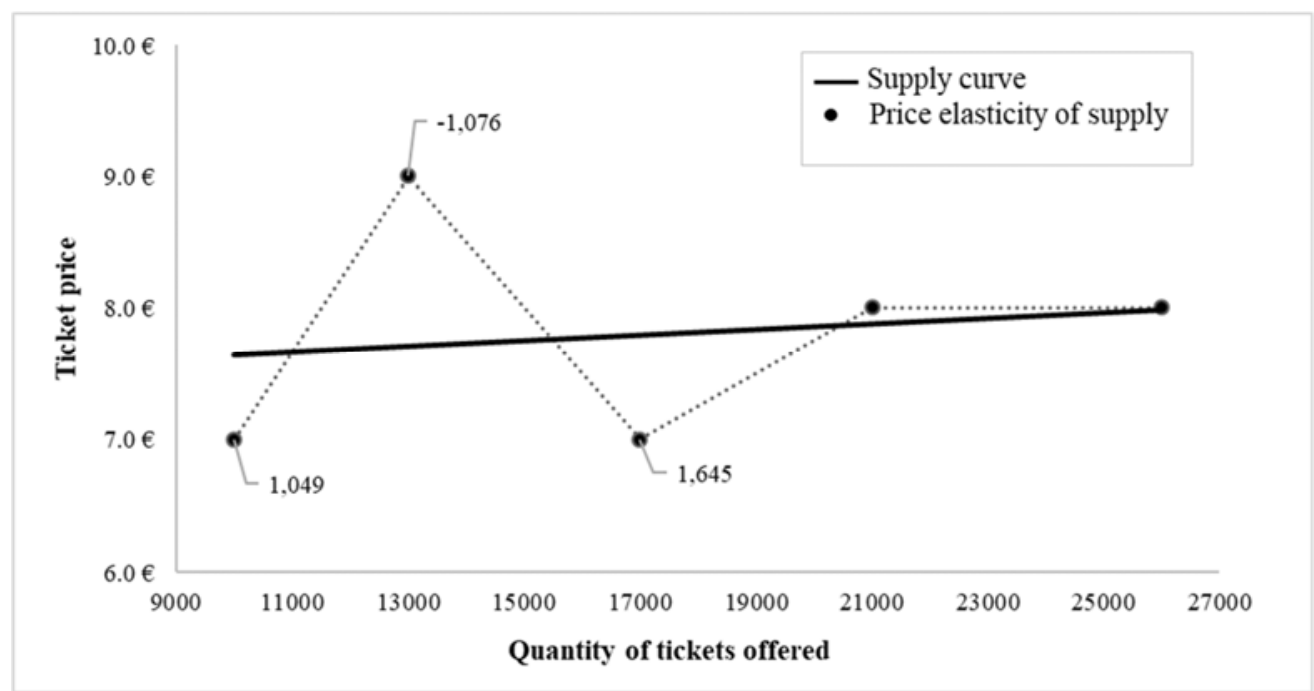

Figure 4. Supply curve and price elasticity of ticket supply

6. The sixth economic concept of "market equilibrium" is derived from analyzing both demand and supply concepts in tickets. More specifically, the intercept of demand and supply curves provides the market equilibrium for the tickets price and quantity. As illustrated in Figure 5, the game administrators-students can gain experience in that based on demand and supply data in Tables $3 \& 5$, the equilibrium is achieved on the price of $9 €$ and the quantity of around 13.000 tickets sold per game.

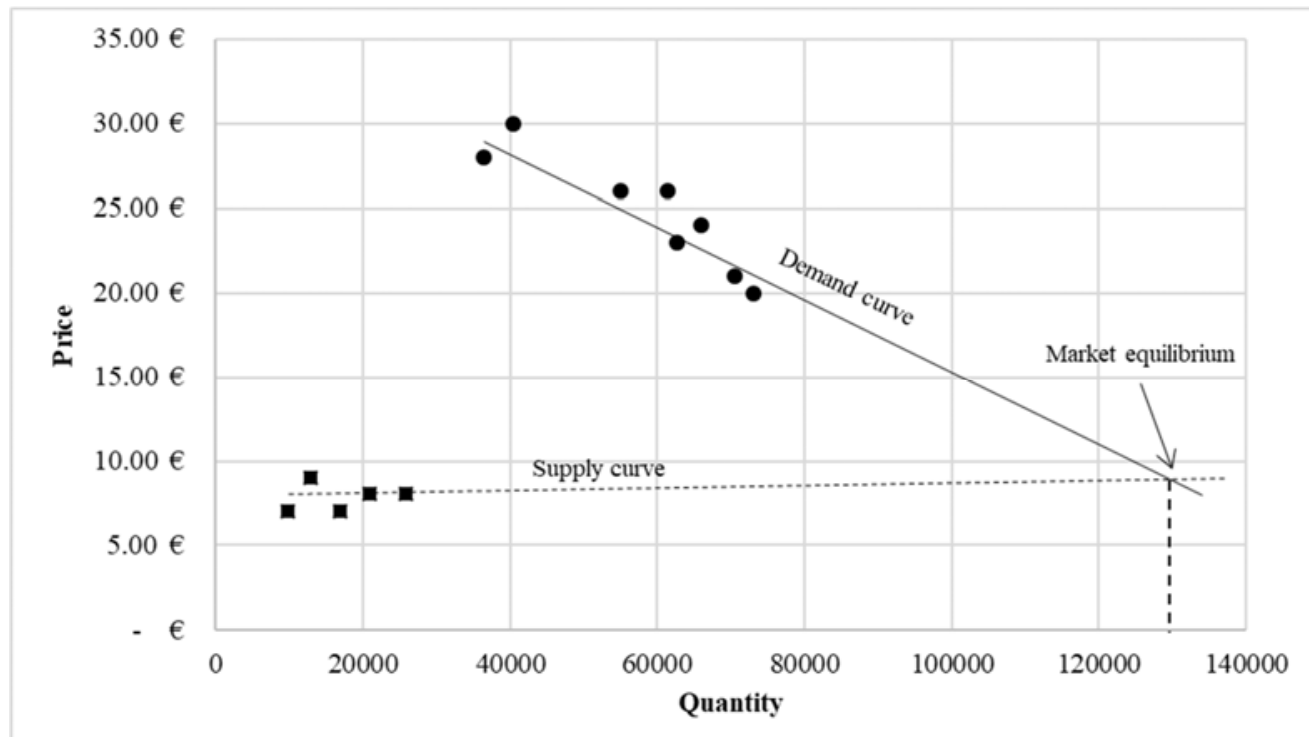

Figure 5. Market equilibrium

7. With concern to the seventh economic concept "direct and indirect costs", the game administrators-students can gain experience in that a number of football club expenses should be taken into consideration. Following data over three seasons (Table 6), value of players' contract and transfer fees are considered as direct costs for playing games. On the other hand, stadium and facilities expenses can be considered indirect cost for competitions' participation. 
Table 6. Direct and indirect cost (in $000 €$ )

\begin{tabular}{c|c|c|c}
\hline Type of cost & Season 1 & Season 2 & Season 3 \\
\hline \multirow{2}{*}{ Direct cost } & Players contract & 13892 & 12439 \\
\cline { 2 - 4 } & Transfer fees & 52820 & 61290 \\
\hline Indirect cost & $\begin{array}{c}\text { Stadium \& facilities } \\
\text { expenses }\end{array}$ & 1652 & 3487 \\
\hline
\end{tabular}

8. The implementation of the eighth economic concept, "fixed and variable costs" it is based on football club expenses over a certain period. As shown in Table 7, the game administrators-students can gain experience in that stadium and facilities expenses can be considered as fixed cost whereas prize bonuses can be considered as variable cost. They should also bare in mind that over long time periods, all type of costs are considered as variable.

Table 7. Fixed and Variable cost (in $000 €$ )

\begin{tabular}{c|c|c}
\hline Day & $\begin{array}{c}\text { Fixed cost: } \\
\text { Stadium \& facilities expenses }\end{array}$ & $\begin{array}{c}\text { Variable cost: } \\
\text { Prize bonus }\end{array}$ \\
\hline 17 & 780 & 600 \\
\hline 18 & & - \\
\hline 19 & & 400 \\
\hline 20 & & 400 \\
\hline 21 & & 500 \\
\hline 22 & & - \\
\hline 23 & & 400 \\
\hline 25 & & 200 \\
\hline
\end{tabular}

9. About the nineth economic concept of "marginal cost", the game administratorsstudents can gain experience in that it can be derived from the increase of stadium capacity in relation to the stadium and facilities expenses. The marginal cost of an additional seat in the stands of the stadium is shown in Table 8. The game administrators-students should bare in mind that in the present application the marginal cost adding a single seat ranges from $155 €$ to $280 €$. Consequently, for a ticket price of $30 €$, a number of five to ten sell-off games are required to pay off the investment.

Table 8. Marginal cost for new stadium seat

\begin{tabular}{c|c|c|c|c|c}
\hline Day & $\begin{array}{c}\text { Stadium capacity } \\
\text { old }\end{array}$ & $\begin{array}{c}\text { Stadium } \\
\text { capacity } \\
\text { new }\end{array}$ & $\begin{array}{c}\text { Added } \\
\text { stadium seats }\end{array}$ & $\begin{array}{c}\text { Stadium \& } \\
\text { facilities } \\
\text { expenses }\end{array}$ & $\begin{array}{c}\text { Marginal cost } \\
\text { for a single seat }\end{array}$ \\
\hline 1 & 68000 & 72000 & 4000 & $780000 €$ & $195 €$ \\
\hline 2 & 72000 & 76000 & 4000 & $620000 €$ & $155 €$ \\
\hline 3 & 76000 & 81000 & 5000 & $1400000 €$ & $280 €$ \\
\hline 4 & 81000 & 86000 & 5000 & $1200000 €$ & $240 €$ \\
\hline
\end{tabular}

10. The tenth economic concept of "breakeven point analysis" can be implemented by the game administrators-students using the revenues generated from tickets sales (stadium attendance and ticket price), as well as the expenses for new seats (stadium and facilities). To interpret the results displayed in Figure 6, the game administrators-students should bare in mind that there is required as a period of nine competition days to pay off the expenses 
or the investment for a stadium upgrade. Consequently, the breakeven point confirms the conclusions derived from the above marginal cost analysis.

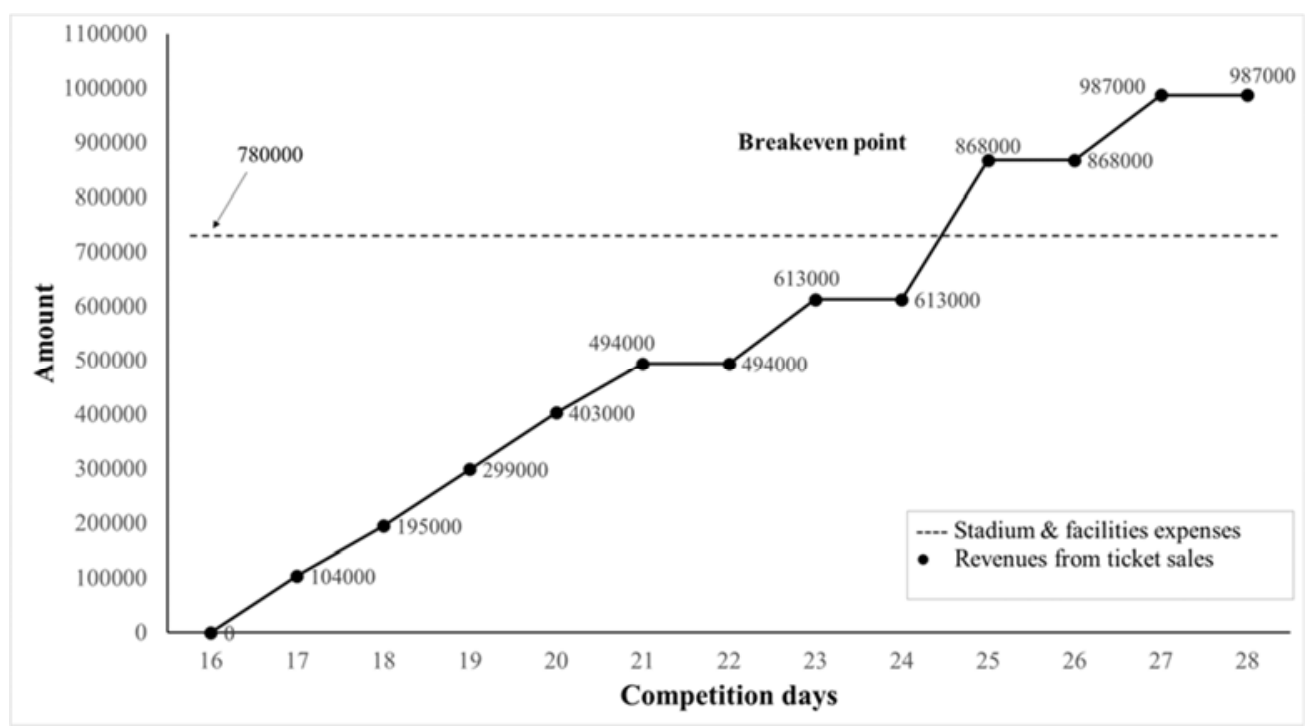

Figure 6. Breakeven point analysis

11. The eleventh economic concept of "pricing" can be applied by the game administrators-students in tickets, by using the marginal cost of new stadium seats. Based on the information provided on Table 8, the game administrators-students learn that the ticket price can be set according to the marginal cost for new seat offered, the stadium capacity, and the projected return on stadium and facilities investment.

12. The twelfth and final economic (accounting) concept of "budget" for a sports club is applyed by the game administrators-students both by the revenues and the expenses in the course of a particular top eleven season. More specifically, the economic results relative to budgetary amounts and their percentage difference are presented in Table 9.

Table 9. Budget, economic results and their \% difference (in 000€)

\begin{tabular}{r|c|r|c|c}
\hline & & Budget & Economic results & Difference \\
\hline \multirow{4}{*}{ Revenues } & Ticket sales & 40000 & 13900 & $-65,25 \%$ \\
\cline { 2 - 5 } & Sponsorships & 50000 & 57970 & $15,94 \%$ \\
\cline { 2 - 5 } & Prize money & 150000 & 203000 & $35,33 \%$ \\
\cline { 2 - 5 } & Players' transfer & 50000 & 94100 & $88,20 \%$ \\
\cline { 2 - 5 } & Merchandising & 10000 & 4180 & $-58,20 \%$ \\
\cline { 2 - 5 } & Total: & $\mathbf{3 0 0 0 0 0}$ & $\mathbf{3 7 3 1 5 0}$ & $\mathbf{2 4 , 3 8 \%}$ \\
\hline \multirow{7}{*}{ Expenses } & Players' contract & 30000 & 42500 & $41,67 \%$ \\
\cline { 2 - 5 } & Players' transfer fee & 150000 & 188000 & $25,33 \%$ \\
\cline { 2 - 5 } & Prize bonus & 20000 & 30600 & $53,00 \%$ \\
\cline { 2 - 5 } & Stadium \&facilities & 50000 & 25500 & $-49,00 \%$ \\
\cline { 2 - 5 } & Total: & $\mathbf{2 5 0 0 0 0}$ & $\mathbf{2 8 6 6 0 0}$ & $\mathbf{1 4 , 6 4 \%}$ \\
\cline { 2 - 5 } & Net Result & $\mathbf{5 0 0 0 0}$ & $\mathbf{8 6 5 5 0}$ & $\mathbf{7 3 , 1 0 \%}$ \\
\hline
\end{tabular}




\section{Conclusion}

The purpose of this study was to explore the possibility of using the sport management game Top Eleven, as an auxiliary educational tool [10], [16], [18]-[22] for teaching sports economics concepts at undergraduate level, dealing among other reasons "learning by doing" [1] "simulates the real world" [3], "motivation through fun offering" [5], [7] with the Covid 19 pandemic's forced digital education [22]. This serious game, since its use goes beyond entertainment [1], [14], [31] simulates the operation of real management systems of professional football clubs and cultivates critical thinking by employing learning processes in a specific field of work [11], [17]. More specifically, it is used as an economic data mining tool [23] depending on players' relevant decision-making and the game's algorithmic operation. The more knowledgable the student-gamer, the more efficient are the economic results, derived from the operation of the created virtual club. This procedure provides a realistic practice of economic management [25] as well as an experiential understanding (as close to real life as posible) of basic sport economic concepts [23], [26], [30].

Concerning the first research question, based on the content analysis of the text book of Nassis [43], there are identified 17 in total economic concepts (see Table 1) taught in the subject "sport economics" in DPESS. Regarding the second research question, there are defined eleven economic sources of data that can be collected from the operation of Top Eleven virtual football club, with the potencial to be used eventually by gamers-students to apply the economic concepts they learn at sport economics class they attend. Under this educational process, as stated by James [38], the student's benefit was to comprehend and gain experience in proper economic decisions by collecting, utilizing, and analyzing relevant data.

Regarding the third research question, a system of collecting relevant data from the operation of the game was created in order to demonstrate how eventually students can gain experience in applying basic economic concepts for the management of a professional football club [33]-[37]. The research protocol for economic data collection involves both daily and seasonal gaming activity. The process of daily recording economic activity to be carried out systematically through the accounting was recommended by Giannoulidou [46]. Following the application of equations or indices and the use of tables and figures, gamersstudents could gain cognitive experience on 12 out of 17 economic concepts identified in the textbook of Nassis [43]. As shown on the implementation results, the assumptions and underlined theory of the examined sport economics concepts are mostly met in a satisfactory degree. Spesifically, the first assumption is to examine whether the serious game can be used as an auxiliary educational tool. To that respect the assumption is met like other similar sport management games [29]. That is, the serious game top eleven possess advanced enough structure to produce the economics realism necessary to act as a life-size field for the application of 12 economic concepts in operational conditions that change according to the decisions of the game administrator and the play conditions.

The second assumption relates to the "underlying theory" of the economic concepts. To that respect the assumption is met as well. In fact, as it is shown in the result Tables and Figures, the serious game possess sophisticated algorithms to the extent that it produces the necessary data for the application of the "economic balance" theory or the rest of the economic concepts in this study, required for the decisions on the educational questions vested to the serious game.

In sum, the popular free online serious game Top Eleven can be used as an educational tool for applying sport economic concepts related to the management of a professional football club. We can argue that based on the above evidence and the results of this study, the game offers a sensible working environment in sport economics and the associated sport management field. The competition to get a job on sport management is so fierce [47], that integrating innovative technology into teaching educational process for field-experience is warranted [11]. As de Freitas and Griffiths [3] argue, by engaging in a serious game, the 
learner acquires an online character or personality simulating the real world. This procedure enables students to be trained in the financial management of a professional sport club in a pleasant and inexpensive way and provides sport management educators an additional training tool in the form of applied exercises.

Further research on students' testing and progress-tracking is needed as an extension of this study, as it holds for any serious game to be considered as a viable educational tool [48]. There are several methods developed by researchers to assess the effectiveness of any serious game. As suggested by Aldrich [1], to demonstrate the desired educational outcome, future research should be concentrated on the measurement effect of students' experience, which is true in the case of Top Eleven. As Corti [18] explains, any serious game's learning experience should be "definable, quantifiable and measurable". Scientific evaluation of future educational scenarios employing game's interaction is also needed [11]. However, even though transfer of learning may be fostered by a game [49], "real" experience on the field cannot be replaced [11].

\section{References}

[1] C. Aldrich, The Complete Guide to Simulations and Serious Games. San Francisco: Pfeiffer, 2009.

[2] M. Graafland, J. M. Schraagen, and M. P. Schijven, "Systematic review of serious games for medical education and surgical skills training," Br. J. Surg., vol. 99, no. 10, pp. 13221330, Sep. 2012, doi: 10.1002/bjs.8819.

[3] S. de Freitas and M. Griffiths, "Online gaming as an educational tool in learning and training," Br. J. Educ. Technol., vol. 38, no. 3, pp. 535-537, May 2007, doi: 10.1111/j.14678535.2007.00720.x.

[4] D. A. Gentile and J. R. Gentile, "Violent games as exemplary teachers," 2005.

[5] M. Prensky, Digital game-based learning. New York: McGraw-Hill, 2001.

[6] F. Paraskeva, S. Mysirlaki, and A. Papagianni, "Multiplayer online games as educational tools: Facing new challenges in learning," Comput. Educ., vol. 54, no. 2, pp. 498-505, Feb. 2010, doi: 10.1016/j.compedu.2009.09.001.

[7] T. A. Papp, "Gamification Effects on Motivation and Learning: Application to Primary and College Students," Int. J. Cross-Disciplinary Subj. Educ., vol. 8, no. 3, pp. 3193-3201, 2017, doi: 10.20533/ijcdse.2042.6364.2017.0428.

[8] J. Fritz and W. Fehr, Computer games: Virtual gaming and learning worlds. Bonn: Federal Agency of Civic Education, 2003.

[9] M. J. P. Wolf, "Genre and the video game," in Handbook of computer game studies, J. Raessens and F. Goldstein, Eds. Cambridge: MIT Press, 2005, pp. 193-204.

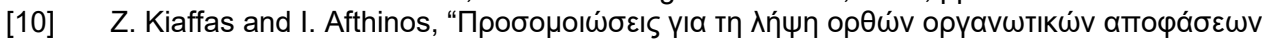

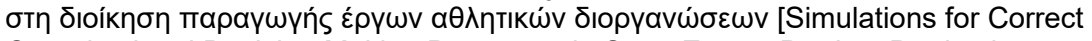
Organizational Decision Making Processes in Sport Events Product Production

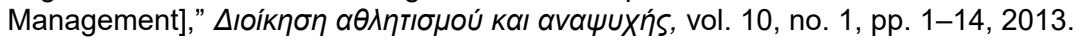

[11] R. Kretschmann, "Digital Sport-Management Games and Their Contribution to Prospective Sport-Managers' Competence Development," Adv. Phys. Educ., vol. 02, no. 04, pp. 179186, 2012, doi: 10.4236/ape.2012.24031.

[12] Top Eleven, "Be a Football Manager." https://www.topeleven.com/.

[13] M. Milošević, N. Živić, and I. Andjelković, "Early churn prediction with personalized targeting in mobile social games," Expert Syst. Appl., vol. 83, pp. 326-332, 2017, doi: 10.1016/j.eswa.2017.04.056.

[14] R. Kretschmann, "Developing competencies by playing digital sports-games," US-China Educ. Rev., vol. 7, no. 2, pp. 67-76, 2010.

[15] Y. Zhonggen, "A Meta-Analysis of Use of Serious Games in Education over a Decade," Int. J. Comput. Games Technol., vol. 2019, no. 3, 2019, doi: 10.1155/2019/4797032.

[16] L. A. Annetta, J. Minogue, S. Y. Holmes, and M. T. Cheng, "Investigating the impact of video games on high school students' engagement and learning about genetics," Comput. Educ., vol. 53, no. 1, pp. 74-85, 2009, doi: 10.1016/j.compedu.2008.12.020.

[17] L. P. Rieber, L. L. Smith, and D. Noah, "The value of serious play," Educ. Technol., vol. 38, no. 6, pp. 29-37, 1998.

[18] K. Corti, "Games-based Learning: a serious business application," Inf. PixelLearning, vol. 34(6), pp. 1-20, 2006.

[19] K. Kiili, "Digital game-based learning: Towards an experiential gaming model," Internet High. Educ., vol. 8, no. 1, pp. 13-24, 2005, doi: 10.1016/j.iheduc.2004.12.001.

[20] S. De Freitas and M. Oliver, "How can exploratory learning with games and simulations 
within the curriculum be most effectively evaluated?," Comput. Educ., vol. 46, no. 3, pp. 249-264, 2006, doi: 10.1016/j.compedu.2005.11.007.

[21] N. Szilas and D. Sutter Widmer, "Mieux comprendre la notion d'intégration entre l'apprentissage et le jeu," EIAH 2009, Actes l'atelier jeux sérieux, pp. 1-12, 2009.

[22] P.-M. Noemí and S. H. Máximo, "Educational games for learning," Univers. J. Educ. Res., vol. 2, no. 3, pp. 230-238, 2014, doi: 10.13189/ujer.2014.020305.

[23] K. Kumar, "Innovative Teaching Methods in Management," Int. J. Manag. Bus. Stud., vol. 4, no. 3, pp. 19-21, 2014

[24] J. C. Beck and M. Wade, Got game. How the gamer generation is reshaping business forever. Boston, MA: Harvard Business School Press, 2005.

[25] K. Hoff, J. Kroll, and C. Fletcher, "Developing a professional perspective," in Contemporary sport management, J. B. Parks, J. Quarterman, and L. Thibault, Eds. Champaign, IL: Human Kinetics, 2007.

[26] A. J. Faria, D. Hutchinson, W. J. Wellington, and S. Gold, "Developments in business gaming: A review of the past 40 Years," Simul. Gaming, vol. 40, no. 4, pp. 464-487, 2009, doi: $10.1177 / 1046878108327585$.

[27] P. Jercic, "What could the baseline measurements predict about decision-making performance in serious games set in the financial context," 2019 11th Int. Conf. Virtual Worlds Games Serious Appl. VS-Games 2019 - Proc., p. 1DUUMY, 2019, doi: 10.1109/VSGames.2019.8864586.

[28] J. Drayer and D. Rascher, "Simulation in sport finance," Simul. Gaming, vol. 41, no. 2, pp. 231-237, 2010, doi: 10.1177/1046878108321872.

[29] A. McFarlane, A. Sparrowhawk, and Y. Heald, "Report on the educational use of games. TEEM (teachers evaluating educational multimedia)," 2002. [Online]. Available: http://www.teem.org.uk/publications/teem_gamesined_full.pdf.

[30] N. Živić, I. Andjelković, T. Özden, M. Dekić, and E. Castronova, "Results of a massive experiment on virtual currency endowments and money demand," PLoS One, vol. 12, no. 10, pp. 1-14, 2017, doi: 10.1371/journal.pone.0186407.

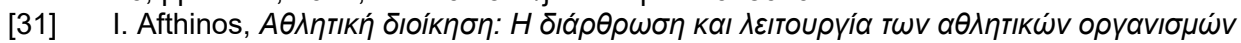
[Sports administration: The structure and operation of sports organizations]. A日ńva: Sport Option, 2017.

[32] T. Susi, M. Johannesson, and P. Backlund, "Serious games -An overview," Skövde, Sweden, 2007.

[33] C. Barnard, The functions of the executive. Cambridge, MA: Harvard University Press, 1938.

[34] S. Beer, The heart of enterprise. Chichester: Wiley \& Sons, 1979.

[35] S. Beer, The brain of the firm, 2nd ed. Chichester: Wiley \& Sons, 1981.

[36] P. R. Lawrence and J. W. Lorsch, Organization and environment. Homewood, IL: Irwin, 1967.

[37] J. G. March and H. A. Simon, Organizations. New York: Wiley, 1958.

[38] P. James, Total Quality Management. Rotterdam: International School of Economics, 1998.

[39] M. L. Tushman and D. A. Nadler, "Information Processing as an Integrating Concept in Organizational Design," Acad. Manag. Rev., vol. 3, no. 3, pp. 613-624, 1978, doi: 10.5465/amr.1978.4305791.

[40] M. A. Leeds and P. von Allmen, The economics of Sports 3rd Ed. Boston, MA: Pearson Education, Inc, 2008.

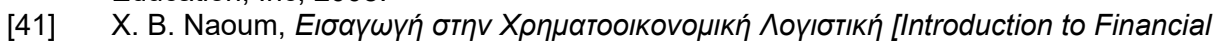

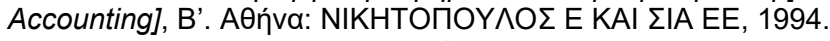

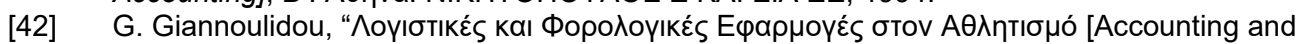

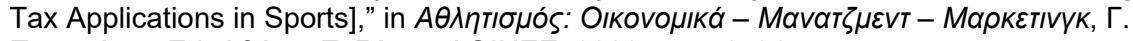

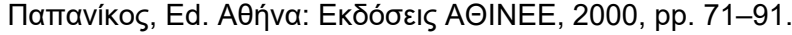

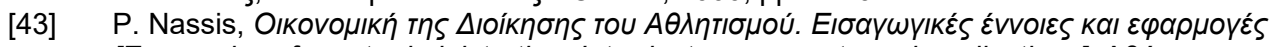
[Economics of sport administration. Introductory concepts and applications]. AӨńva:

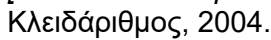

[44] R. Weber, "Basic content analysis," in Research Practice. International Handbooks of Quantitative Application in the Social Sciences, M. Lewis-Beck, Ed. London: Sage, 1995.

[45] H. G. Demmert, The Economics of Professional Team Sport. London: Lexington Books, 1973.

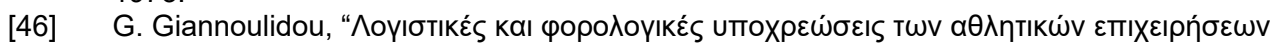

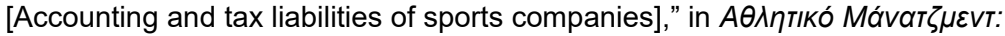

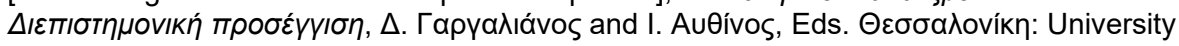
Studio Press, 2001, pp. 151-167.

[47] S. Field, Career opportunities in the sports industry, 4th ed. New York: Ferguson, 2010.

[48] F. Bellotti, B. Kapralos, K. Lee, P. Moreno-Ger, and R. Berta, "Assessment in and of serious games: An overview," Adv. Human-Computer Interact., vol. 2013, 2013, doi: 10.1155/2013/136864.

[49] J. P. Gee, "What video games have to teach us about learning and literacy," Comput. 
Entertain., vol. 1, no. 1, pp. 20-20, Oct. 2003, doi: 10.1145/950566.950595. 